\title{
EFEITO DO TIPO DE CORTE E DE SANIFICANTES NO ESCURECIMENTO DE PEQUI MINIMAMENTE PROCESSADO
}

\author{
Effect of cutting type and sanitizers on the browning of fresh cut peki fruit
}

\author{
Luiz José Rodrigues', Eduardo Valério de Barros Vilas Boas², Nélio Ranieli Ferreira de Paula, \\ Daniella Moreira Pinto ${ }^{2}$, Roberta Hilsdord Piccoli ${ }^{2}$
}

\begin{abstract}
RESUMO
Conduziu-se este trabalho, com o objetivo de avaliar a influência dos sanificantes hipoclorito de sódio ( $\mathrm{NaClO})$ e de peróxido de hidrogênio $\left(\mathrm{H}_{2} \mathrm{O}_{2}\right)$ em diferentes concentrações sobre a vida de prateleira de pequi (Caryocar brasilense Cambess.) submetido a dois tipos de processamento mínimo: "caroço fatiado" e "caroço inteiro", e armazenados a $6 \pm 1^{\circ} \mathrm{C}$ e 90 a $95 \%$ UR, durante 15 dias. $\mathrm{O}$ experimento foi conduzido em delineamento inteiramente casualizado, disposto em um fatorial 2 × 6 × 5, ou seja, 2 tipos de processamento (caroços "fatiados" e "inteiros"), 6 tempos ( $0 \mathrm{~h}, 3,6,9,12,15$ dias) e 5 tratamentos (controle, $\mathrm{NaClO} 50 \mathrm{ppm}, \mathrm{NaClO}$ 100 ppm, $\mathrm{H}_{2} \mathrm{O}_{2} 4 \%$ e $\mathrm{H}_{2} \mathrm{O}_{2} 6 \%$ ), com 3 repetições. A cada três dias foram realizadas as análises: vitamina C, polifenoloxidase, peroxidase e cor (CIE $\mathrm{L}^{*} \mathrm{a} \mathrm{a}^{*}$ ). O pequi minimamente processado apresentou decréscimo nos teores de vitamina $\mathrm{C}$ ao longo do armazenamento. $\mathrm{O}$ caroço fatiado mostrou-se com maior atividade da enzima polifenoloxidase em relação ao inteiro. A interação significativa entre o corte, o sanificante e o tempo ocorreu para a variável peroxidase, tendo sido observado para o caroço fatiado tratado com os sanificantes $\mathrm{H}_{2} \mathrm{O}_{2} 4$ e $6 \%$ maior atividade dessa enzima. Observou-se a redução do valor de $\mathrm{L}^{*}$, durante o armazenamento do pequi minimamente processado, independente do sanificante utilizado, ocasionado pelo escurecimento do produto.
\end{abstract}

Termos para indexação: Caryocar brasiliense, qualidade, processamento mínimo, enzimas.

\section{ABSTRACT}

The objective of the present work was to evaluate the influence of the sanitizers sodium hypochlorite ( $\mathrm{NaClO}) 50$ and $100 \mathrm{ppm}$ and $4 \%$ and $6 \%$, hydrogen peroxide $\left(\mathrm{H}_{2} \mathrm{O}_{2}\right)$ on the shelf life of fresh cut peki fruit (Caryocar brasilense Cambess.) submitted to two sorts of processing: "sliced stone" and whole stone", stored at $6 \pm 1^{\circ} \mathrm{C}$ and 90 to $95 \%$ of RH for 15 days. The analyses were performed every three days. The experiment was conducted in a completely randomized design arranged by a $2 \times 6 \times$ 5 factorial, i.e. 2 sorts of processing ("sliced and whole stones"), 6 times ( $0 \mathrm{~h}, 3,6,9,12,15$ days) and 5 treatments (control, $50 \mathrm{ppm}$ $\mathrm{NaClO}, 100 \mathrm{ppm} \mathrm{NaClO}, 4 \% \mathrm{H}_{2} \mathrm{O}_{2}$ and $6 \% \mathrm{H}_{2} \mathrm{O}_{2}$ ), with 3 replicates. Every three days, the following analyses were conducted: vitamin C, polyphenoloxidase, peroxidase and color (CIE L*a*b*). The fresh cut peki fruit showed decreases in the contents of vitamin $\mathrm{C}$ during storage. The sliced stones showed itself with an increased activity of the enzyme polyphenoloxidase relative the whole one. The significant interaction cutting sanitizer and time was found for peroxidase, the sliced stones and the sanitizers $4 \%$ and $6 \% \mathrm{H}_{2} \mathrm{O}_{2}$ having promoted the highest activity of that enzyme. Reduced value $\mathrm{L}^{*}$ during the storage of fresh cut peki fruit was observed, independent of the used sanitizer, suggesting browning of the product.

Index terms: Caryocar brasiliense, quality, minimal processing, enzymes.

\section{(Recebido em 17 de março de 2009 e aprovado em 10 de agosto de 2010)}

\section{INTRODUÇÃO}

Segundo a International Fresh-Cut Produce Association - IFPA (2005), produtos minimamente processados (ou "fresh cut", ou levemente processados, ou parcialmente processados) são definidos como qualquer fruta ou hortaliça, ou ainda qualquer combinação delas, que foi alterada fisicamente, a partir de sua forma original, embora mantenha o seu estado fresco. Independente do tipo, ele é selecionado, lavado, descascado e cortado, resultando num produto $100 \%$ aproveitável que posteriormente é embalado ou pré-embalado com o intuito de oferecer aos consumidores frescor, conveniência e qualidade nutricional. $\mathrm{O}$ processamento mínimo ainda agrega valor ao produto, aumentando a competitividade do setor de produção e proporcionando meios alternativos de comercialização. Dessa forma, pode-se reduzir as perdas da matéria-prima, com grande impacto econômico e social (Chitarra, 1998).

O pequi é um fruto perecível cuja vida pós-colheita (pós-abscisão) é inferior, normalmente, a uma semana,

'Universidade Federal de Mato Grosso/UFMT - Faculdade de Nutrição/FANUT - Departamento de Alimentos e Nutrição/DAN - Avenida Fernando Corrêa da Costa - 2367 - Bairro Boa Esperança - 78060-900 - Cuiabá, MT - rodrigues.lui3@uol.com.br

2Universidade Federal de Lavras/UFLA - Departamento de Ciência dos Alimentos/DCA - Lavras, MG

${ }^{3}$ Instituto Federal de Educação, Ciência e Tecnologia de Rondônia/IFRO - Colorado do Oeste, RO 
quando armazenado à temperatura ambiente. Seu período de conservação depende, principalmente, de seu estado físico e do estádio de maturação, no início do armazenamento, embora seja influenciado pelas condições edafoclimáticas às quais foi submetido antes da abscisão ou colheita (Vilas-Boas, 2004).

$\mathrm{O}$ pequi ainda apresenta o inconveniente de possuir o endocarpo espinhoso aderido ao mesocarpo interno, que é a porção comestível. Parte do endocarpo espinhoso chega até mesmo a se confundir, morfologicamente, com o mesocarpo interno. A presença dos espinhos limita o consumo do pequi e sua expansão na culinária brasileira (Vilas-Boas, 2004).

O processamento mínimo do pequi leva em consideração a extração do caroço, com a possibilidade do seu fatiamento, visando a um mesocarpo interno isento de espinhos. O caroço é constituído por tecidos vivos com aproximadamente $50 \%$ de água, além de óleos, carboidratos e proteínas, que podem servir de substrato para microrganismos, como fungos e bactérias que se desenvolvem bem em ambientes com alto teor de umidade. $\mathrm{O}$ caroço, como um órgão vegetal constituído por tecidos vivos, respira. Quanto mais rapidamente respira, mais rapidamente tem seus substratos queimados. Como a qualidade dos frutos é dependente de sua composição química, obviamente, a queima dos substratos de reserva pode levar, dependendo do nível, ao comprometimento de sua qualidade, sob a perspectiva nutricional e sensorial (Vilas-Boas, 2004).

Um aspecto não menos importante no processamento mínimo de frutos é o escurecimento enzimático. A descoloração, ou escurecimento, na superfície de frutas cortadas pode ocorrer em decorrência da descompartimentação que ocorre quando as células são rompidas, liberando e colocando em contato substratos e oxidases. $\mathrm{O}$ ferimento também induz a síntese de algumas enzimas envolvidas nas reações de escurecimento ou a biossíntese de substratos (Rolle \& Chism, 1987). Enzimas de células rompidas estão livres para misturar-se com substratos, produzindo compostos de coloração escura. $\mathrm{O}$ escurecimento dos tecidos dos frutos se dá, principalmente, pela oxidação de compostos fenólicos, reação esta catalisada por duas enzimas: a polifenoloxidase (PFO) e a peroxidase (PER) (Braverman, 1967; Teisson, 1979).

Outro fator que pode ser considerado limitante, do ponto de vista da qualidade, é que os pequis normalmente são coletados do chão (Vilas-Boas, 2004). A maioria dos frutos, quando maduros, se desprendem da "planta-mãe" caindo ao chão e entrando em contato direto com o solo, tornando-se veículo de contaminação e fonte de microrganismos patogênicos que podem se instalar na sua superfície.
Neste trabalho, objetivou-se verificar a influência dos tipos de corte (caroço fatiado e caroço inteiro) e os sanificantes hipoclorito de sódio $(\mathrm{NaClO})$ e peróxido de hidrogênio $\left(\mathrm{H}_{2} \mathrm{O}_{2}\right)$, em diferentes concentrações, sobre o escurecimento de pequi (Caryocar brasiliense Cambess.)minimamente processado, armazenado a $6^{\circ} \mathrm{C}$, durante 15 dias.

\section{MATERIAL E MÉTODOS}

\section{Matéria-prima}

Foram utilizados pequis (Caryocar brasiliense) provenientes da cidade de Itumirim, situada no Sul do Estado de Minas Gerais. Pela manhã, os frutos foram coletados, ao acaso, do chão e, em alguns casos, colhidos quando ainda estavam unidos à planta-mãe, porém, apresentavam rachaduras no epicarpo e mesocarpo externo, expondo o mesocarpo interno. Em seguida, procedeu-se à seleção quanto a aparência, a ausência de injúrias e podridões, a ausência de cheiro característico de deterioração e quanto ao grau de maturação (polpa com coloração amarelada).

\section{Processamento dos frutos}

No laboratório, os frutos foram novamente selecionados, objetivando tornar o lote o mais uniforme possível quanto ao grau de maturação e a ausência de danos mecânicos ou podridões.

Os pequis tiveram as superfícies lavadas com detergente neutro para remoção de sujidades grosseiras provenientes do campo. Posteriormente, foram enxaguados em água corrente até a completa remoção do detergente.

Após a lavagem, os frutos foram armazenados imediatamente em câmara fria a $12 \pm 1^{\circ} \mathrm{C}$ e umidade relativa (UR) entre $90 \%$ a $95 \%$, por aproximadamente 15 horas.

Após esse período, os pequis foram levados para a Sala de Processamento Mínimo, sendo descascados manualmente com o auxílio de facas afiadas. Em metade dos frutos coletados, o caroço foi deixado intacto, enquanto na outra metade, os caroços contendo o mesocarpo interno (polpa) foram fatiados no sentido longitudinal, utilizandose um fatiador manual de aço inoxidável, tomando-se o cuidado de retirar apenas o mesocarpo interno, evitando atingir o endocarpo espinhoso, de modo que as fatias se apresentaram com aproximadamente $0,2 \mathrm{~cm}$ de espessura.

Os caroços "inteiros" e os "fatiados" foram imersos nas soluções que correspondiam aos tratamentos durante 5 minutos; controle: imersão em água pura a $8^{\circ} \mathrm{C}$, hipoclorito de sódio $(\mathrm{NaClO}) 50 \mathrm{ppm}$ e 100 ppm a $8^{\circ} \mathrm{C}$, peróxido de hidrogênio $\left(\mathrm{H}_{2} \mathrm{O}_{2}\right) 4 \%$ e $6 \%$ a temperatura ambiente $\left(23^{\circ} \mathrm{C}\right)$.

Em todos os tratamentos, verificou-se o $\mathrm{pH}$ das soluções. Para o $\mathrm{NaClO} 50$ e 100 ppm, correspondeu a 6,5 
e 6,8, respectivamente; já para o $\mathrm{H}_{2} \mathrm{O}_{2} 4 \%$ e $6 \%$, os valores de $\mathrm{pH}$ foram de 5,5 e 5,8, respectivamente e o controle (água) apresentou pH em torno de 6,0.

Decorrido o tempo de imersão, os frutos minimamente processados foram centrifugados a $750 \mathrm{rpm}$, durante 1 minuto, para drenagem do excesso de líquido. Cada parcela constituiu de dez caroços inteiros e cerca de 100 gramas de caroços fatiados acondicionados em bandejas plásticas $(10 / 20 \mathrm{~cm})$ envoltas por filme de policloreto de vinila (PVC) de $15 \mu \mathrm{m}$, flexível e autoadesível, previamente higienizadas.

As embalagens foram armazenadas em câmara fria a $6 \pm 1^{\circ} \mathrm{C}$ e $90 \%$ a $95 \%$ UR, durante um período de 15 dias e as análises realizadas a cada três dias.

\section{Análises}

Vitamina C - O teor de ácido ascórbico (após a oxidação a ácido deidroascórbico) foi determinado pelo método colorimétrico, utilizando-se 2,4 dinitrofenilhidrazina, segundo Strohecker \& Henning (1967). Os resultados foram expressos em mg de ácido ascórbico por $100 \mathrm{~g}$ de polpa.

Polifenoloxidase (PFO) - A extração da polifenoloxidase foi realizada de acordo com o método proposto por Matsumo \& Uritane (1972) e a atividade expressa em unidade (capacidade de alterar 0,001 de absorbância) por minuto, por grama de tecido fresco $(\mathrm{U} / \mathrm{min} / \mathrm{g})$, segundo o método de Teisson (1979).

Peroxidase (PER) - A extração e a determinação da peroxidase foram realizadas conforme metodologia preconizada por Flurkey \& Jen (1978). A atividade enzimática foi expressa em $\mathrm{UA} \mathrm{h}^{-1}$, definida como teor de enzima que produz aumento de 0,1 na absorção $0,1 \mathrm{DO}$ por minuto, a 470 e $420 \mathrm{~nm}$, respectivamente.

Coloração - A cor foi determinada em dez pontos distintos dos caroços do pequi minimamente processados na forma de "fatias" e na forma "inteiro", fazendo-se três leituras em cada fruto que formava a bandeja. Foi utilizado o colorímetro Minolta CR-400, com a determinação no modo CIE L*a*b*. A coordenada $\mathrm{L}^{*}$ representa quanto mais clara ou mais escura é a amostra, com valores variando de 0 (totalmente preta) a 100 (totalmente branca); a coordenada $a^{*}$ pode assumir valores de $-80 \mathrm{a}+100$, em que os extremos correspondem ao verde e ao vermelho, respectivamente; e a coordenada $b^{*}$ com a intensidade de azul ao amarelo, que pode variar de -50 (totalmente azul) a +70 (totalmente amarelo).

Análise estatística - realizada com o auxílio do programa estatístico SISVAR 4.0 (Nunes, 2010). Os dados obtidos foram submetidos à análise de variância aplicada ao DIC, sendo que os tratamentos analisados em função do tempo foram aleatorizados, conforme o esquema de parcela subdividida. As médias de tratamentos, quando significativas, foram comparadas pelo teste de Tukey a $1 \%$ e $5 \%$ de probabilidade. Já os modelos de regressões polinomiais foram selecionados com base na significância do teste de F de cada modelo testado e também pelo coeficiente de determinação.

Delineamento experimental - o experimento foi conduzido em delineamento inteiramente casualizado (DIC), em esquema fatorial 2 × 6 × 5, ou seja, 2 tipos de processamento (caroços "fatiados" e "inteiros"), 6 tempos (0h, 3, 6, 9, 12, 15 dias) e 5 tratamentos (controle, $\mathrm{NaClO} 50 \mathrm{ppm}, \mathrm{NaClO}$ 100 ppm, $\mathrm{H}_{2} \mathrm{O}_{2} 4 \%$ e $\mathrm{H}_{2} \mathrm{O}_{2} 6 \%$ ), com 3 repetições.

\section{RESULTADOS E DISCUSSÃO}

Observou-se efeito significativo apenas do tempo de armazenamento $(\mathrm{p}<0,01)$ para a variável vitamina $\mathrm{C}$, que não foi influenciada pelo tipo de corte, tampouco pelos sanificantes.

$\mathrm{O}$ pequi minimamente processado apresentou diminuição nos teores de vitamina $\mathrm{C}$ ao longo do armazenamento, chegando a uma perda de 48,93\% (Figura 1).

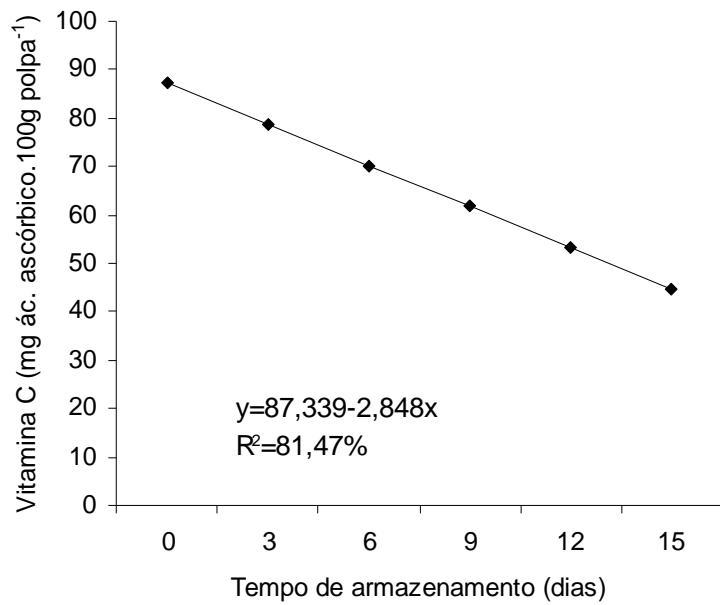

Figura 1 - Valores médios, equação de regressão e coeficiente de determinação de vitamina $\mathrm{C}$ em pequi minimamente processado submetido a tratamentos com $\mathrm{NaClO}$ e $\mathrm{H}_{2} \mathrm{O}_{2}$, em diferentes concentrações, armazenado a $\pm 6^{\circ} \mathrm{C}$ por 15 dias.

Arruda et al. (2008) também relataram perdas expressivas em frutas cítricas minimamente processadas após 6 dias de armazenamento, da ordem de 33,5\%. Por outro lado, essas perdas representam de 3 a 4 vezes mais em manga e mamão minimamente processados. Vilas-Boas et al. (2006) observaram perdas na ordem de $10 \%$ de vitamina $\mathrm{C}$ em mangas minimamente processadas, armazenadas durante 12 dias. Esse comportamento é inerente ao processamento mínimo, pois os danos mecânicos 
causados pelo corte nos tecidos promovem a desorganização celular, ocasionando a oxidação do ácido ascórbico.

Segundo Chitarra (1998), o ácido ascórbico pode ser oxidado por uma série de mecanismos bioquímicos que são responsáveis não só pela perda de sua atividade vitamínica, como também pela formação de pigmentos escuros. Diferentes enzimas podem catalisar a sua degradação direta (ácido ascórbico oxidase) ou indireta (peroxidase, polifenoloxidase e citocromo oxidase). De acordo com Lee \& Kader (2000), produtos hortícolas severamente cortados ou picados perdem muita vitamina $\mathrm{C}$.

Houve efeito significativo da interação entre o corte e o tempo de armazenamento para a atividade da enzima polifenoloxidase, que não foi influenciada pelo fator sanificante.

A atividade da PFO aumentou linearmente com o período de armazenamento, tendo o caroço fatiado (a) apresentado maiores valores dessa enzima do que o inteiro (b), durante todo o armazenamento (Figura 2).

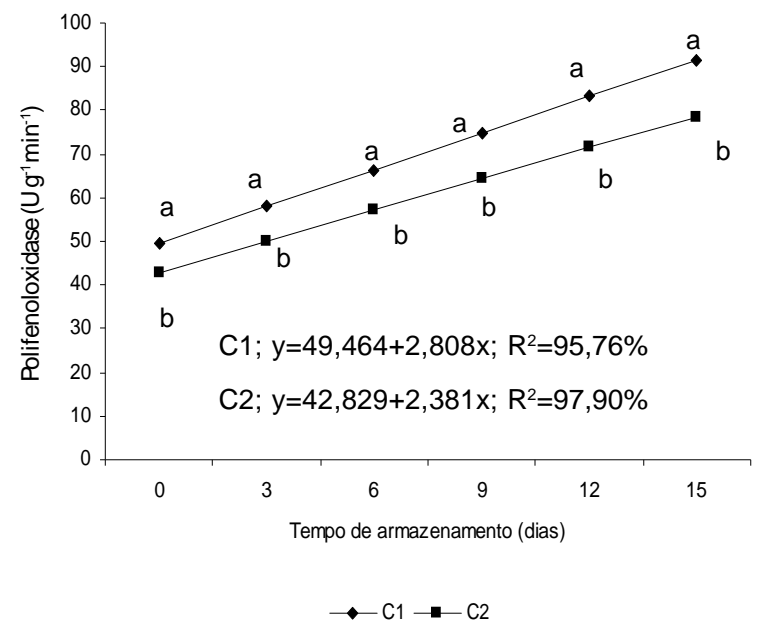

Figura 2 - Valores médios, equações de regressão e coeficientes de determinação para a variável polifenoloxidase (PFO) em pequi minimamente processado submetido a diferentes cortes: $\mathrm{C} 1=$ "fatiado" e $\mathrm{C} 2=$ "inteiro" em tratamentos com $\mathrm{NaClO}$ e $\mathrm{H}_{2} \mathrm{O}_{2}$, em diferentes concentrações, armazenado a $\pm 6^{\circ} \mathrm{C}$ por 15 dias.

*Médias seguidas da mesma letra entre as equações de regressão representam semelhanças estatísticas entre os cortes, a 5\% de probabilidade, pelo teste de Scott-Knott.

No caroço fatiado, a atividade da polifenoloxidase variou de 49,464 a 91,592 $\mathrm{U} \mathrm{g}^{-1} \mathrm{~min}^{-1}$; já, no caroço inteiro, essa variação foi de 42,829 a 78,545 $\mathrm{U} \mathrm{g}^{-1} \mathrm{~min}^{-1}$ (Figura 2).
A descoloração, ou escurecimento na superfície de frutas e hortaliças cortadas pode ocorrer em razão da descompartimentalização que ocorre quando as células são rompidas, liberando e colocando em contato enzimas e substratos (Rolle \& Chism, 1987). A principal enzima associada com o escurecimento em frutos é a polifenoloxidase. Essa enzima reage com alguns substratos endógenos, tais como o-diidroxifenois, produzindo pigmentos de coloração marrom (King Junior \& Bolin, 1989). O escurecimento oxidativo na superfície cortada é um fator limitante no armazenamento de frutas e hortaliças minimamente processadas (Brecht, 1995).

O escurecimento no pequi minimamente processado em resposta a injúrias do fatiamento pode ser decorrente do teor de compostos fenólicos presentes no fruto, em torno de 102,372 mg.100 g-1 de polpa (Rodrigues et al., 2009). O ferimento induz o colapso celular, que promove o contato dos fenólicos presentes com a PFO, resultando no escurecimento do pequi.

A enzima peroxidase foi afetada significativamente pela interação tripla entre corte, sanificante e tempo de armazenamento $(\mathrm{p}<0,01)$.

Observou-se incremento linear na atividade da PER dos caroços fatiados e inteiros, a despeito da sanificação, à exceção dos caroços fatiados sanificados com $\mathrm{H}_{2} \mathrm{O}_{2} 6 \%$, que apresentaram um comportamento quadrático da atividade dessa enzima, com incremento até o $12^{\circ}$ dia, seguido de estabilização (Figura 3 ). A peroxidase catalisa reações redox em vegetais, usando tanto o peróxido de hidrogênio como o oxigênio como aceptores de hidrogênio, com mecanismo de ação baseado na formação de complexos enzima - doador de hidrogênio, sendo encontrada no citoplasma (forma solúvel), na parede celular (forma insolúvel), membranas e organelas das células vegetais. $\mathrm{O}$ aumento da atividade de PER pode estar associado com a biossíntese de compostos da parede celular, em resposta a danos mecânicos nos tecidos, resistência a doenças e nos mecanismos de cura ou reparo de ferimento dos tecidos (Chitarra \& Chitarra, 2005). Elevados níveis dessa enzima estão correlacionados com a deterioração oxidativa de frutas que se encontram em estádio avançado de amadurecimento ou senescência. Assim, o aumento de PER, durante o armazenamento do pequi, pode ter ocorrido em função das injúrias causadas no fruto em decorrência do processamento mínimo.

Os sanificantes não influenciaram na atividade da PER até o $3^{\circ}$ dia de armazenamento. $\mathrm{O} \mathrm{H}_{2} \mathrm{O}_{2}$ determinou maior atividade da enzima PER em relação aos demais sanificantes utilizados, nos caroços fatiados do $6^{\circ}$ ao $12^{\circ}$ 

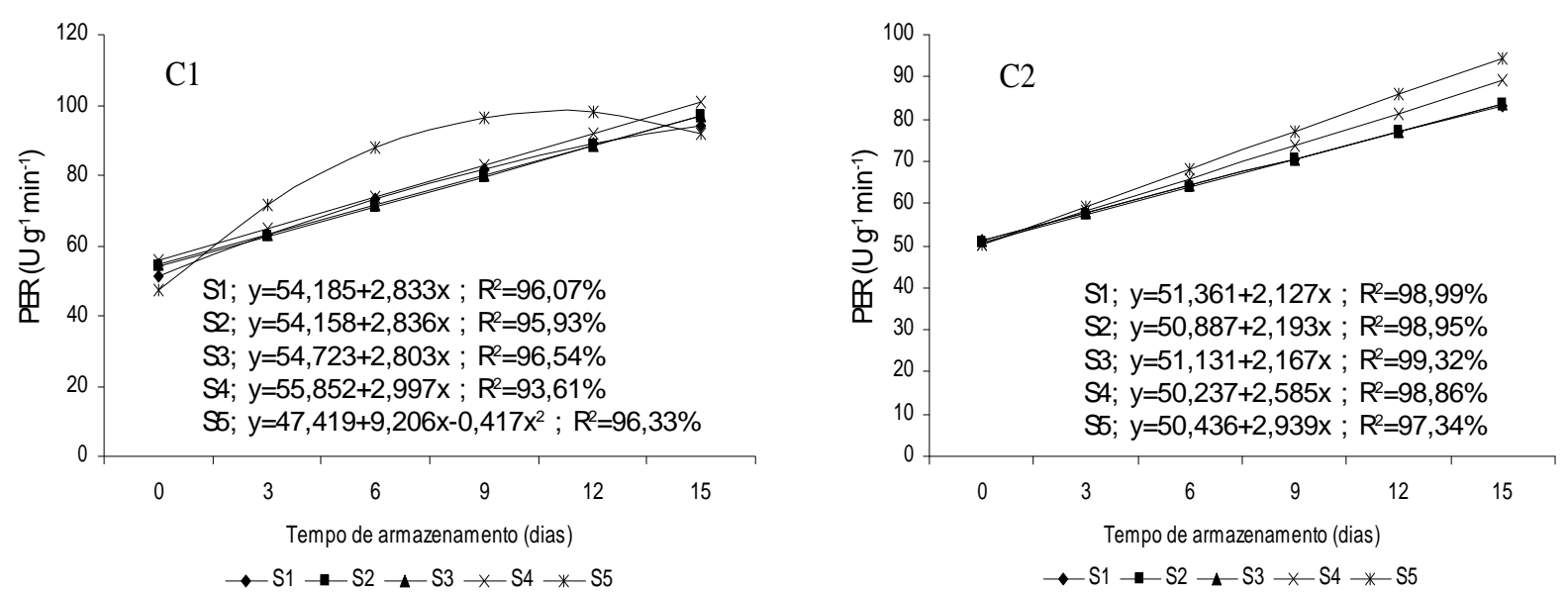

Figura 3 - Valores médios, equações de regressão e coeficientes de determinação da peroxidase (PER) do pequi minimamente processado (C1= "Fatiado" e C2= "Inteiro") submetido aos tratamentos: $\mathrm{S} 1=\mathrm{Controle}, \mathrm{S} 2=\mathrm{NaClO}$ $50 \mathrm{ppm}, \mathrm{S} 3=\mathrm{NaClO} 100 \mathrm{ppm}, \mathrm{S} 4=\mathrm{H}_{2} \mathrm{O}_{2} 4 \%$ e $\mathrm{S} 5=\mathrm{H}_{2} \mathrm{O}_{2} 6 \%$, armazenado a $\pm 6^{\circ} \mathrm{C}$ por 15 dias.

dias e nos caroços inteiros do $9^{\circ}$ ao $15^{\circ}$ dias. Não foi observado efeito dos sanificantes sobre a atividade da PER nos caroços fatiados, aos 15 dias de armazenamento (Tabela 1).

Caroços inteiros, aos 6 dias de armazenamento, apresentaram maior atividade de PER quando sanificados com $\mathrm{H}_{2} \mathrm{O}_{2} 6 \%$, em comparação aos caroços submetidos aos demais sanificantes, incluindo o controle, que não diferiram entre si (Tabela 1). Este efeito pode estar associado à capacidade dessa enzima em catalisar a oxidação de alguns compostos amínicos aromáticos de outros fenólicos na presença do peróxido de hidrogênio com posterior formação de polímeros escuros. A peroxidase promove a oxidação de compostos fenólicos na presença de peróxido de hidrogênio (Dunford \& Stillman, 1976). A liberação de peróxido de hidrogênio na oxidação de alguns compostos fenólicos, catalisada pela polifenoloxidase, poderia indicar uma possível ação sinergística entre essas duas enzimas, o que sugere a participação da peroxidase nos processos de escurecimento (Subramanian et al., 1999).

$\mathrm{O}$ valor $\mathrm{L}^{*}$ foi afetado significativamente apenas pela interação sanificante e tempo de armazenamento $(\mathrm{p}<0,01)$.

Observou-se redução para o valor de $\mathrm{L}^{*}$ durante o armazenamento do pequi minimamente processado, independente do sanificante utilizado (Figura 4), sugerindo o escurecimento do produto. Essa redução no valor $L^{*}$ pode estar associada ao aumento verificado nas atividades das enzimas PFO e PER, ao longo do armazenamento (Figuras 2, 3).
As amostras tratadas com o $6 \%$ do sanificante $\mathrm{H}_{2} \mathrm{O}_{2}$ apresentaram os menores valores de $\mathrm{L}^{*}$, o que também pode ser associado à maior atividade de PER observada nas amostras tratadas com esse sanificante (Tabela 1).

O escurecimento enzimático, prejudica as propriedades sensoriais dos produtos, porque está associado também a mudanças no sabor e no amaciamento (Martinez \& Whitaker, 1995). O processo enzimático pode estar associado a um grande número de reações oxidativas e de biodegradação, como degradação da clorofila ou auxinas, oxidação de fenóis, oxidação do ácido indol acético e biossíntese de ligninas (Valderrama et al., 2001). Uma vez quebrada a integridade das paredes celulares e das membranas celulares, a oxidação enzimática ocorre de forma muito mais acentuada.

$\mathrm{O}$ valor $\mathrm{a}^{*}$ não foi influenciado por nenhum dos fatores avaliados, uma vez que nem o verde nem o vermelho são as colorações predominantes na parte comestível (mesocarpo interno) do pequi.

A coordenada $b^{*}$ foi afetada significativamente apenas pelo fator tempo de armazenamento $(p<0,01)$.

Verificou-se que os valores de $b^{*}$ reduziram com o período de armazenamento (Figura 5). Essa redução indica que o pequi minimamente processado levou a uma diminuição da coloração amarela. O processo metabólico associado a essa mudança de cor é a degradação dos carotenóides, sobretudo o $\beta$-caroteno, cuja cor característica é a amarela (Cross, 1987), ressaltando que o pequi é uma fruta com altos teores desse carotenóide (Vilas-Boas, 2004).

Entre os fatores que interferem na degradação dos carotenóides estão a luz, o calor e o oxigênio, dentre outros (Britton, 1992). 
Tabela 1 - Valores médios da atividade de peroxidase (PER) em pequi minimamente processado $(\mathrm{C} 1=$ Fatiado e $\mathrm{C} 2=$ Inteiro) submetido aos tratamentos: $\mathrm{S} 1=$ Controle, $\mathrm{S} 2=\mathrm{NaClO} 50 \mathrm{ppm}, \mathrm{S} 3=\mathrm{NaClO} 100 \mathrm{ppm}, \mathrm{S} 4=\mathrm{H}_{2} \mathrm{O}_{2} 4 \%$ e $\mathrm{S} 5=\mathrm{H}_{2} \mathrm{O}_{2} 6 \%$, armazenado $\mathrm{a} \pm 6^{\circ} \mathrm{C}$ por 15 dias.

\begin{tabular}{|c|c|c|c|c|c|c|}
\hline \multicolumn{7}{|c|}{ Tempo de armazenamento (dias) } \\
\hline \multirow[b]{2}{*}{ Sanificantes } & \multicolumn{2}{|c|}{0} & \multicolumn{2}{|c|}{3} & \multicolumn{2}{|c|}{6} \\
\hline & $\mathrm{C} 1$ & $\mathrm{C} 2$ & $\mathrm{C} 1$ & $\mathrm{C} 2$ & $\mathrm{C} 1$ & $\mathrm{C} 2$ \\
\hline S1 & $49,80 \mathrm{aA}$ & $51,13 \mathrm{aA}$ & $65,01 \mathrm{aA}$ & $56,37 \mathrm{bA}$ & $75,81 \mathrm{aA}$ & $66,12 \mathrm{bA}$ \\
\hline $\mathrm{S} 2$ & $49,66 \mathrm{aA}$ & $50,73 \mathrm{aA}$ & $65,00 \mathrm{aA}$ & $56,14 \mathrm{bA}$ & $75,87 \mathrm{aA}$ & $66,18 \mathrm{bA}$ \\
\hline S3 & $50,82 \mathrm{aA}$ & $51,26 \mathrm{aA}$ & $65,05 \mathrm{aA}$ & $56,46 \mathrm{bA}$ & $76,00 \mathrm{aA}$ & $65,46 \mathrm{bA}$ \\
\hline S4 & $50,54 \mathrm{aA}$ & $51,13 \mathrm{aA}$ & $65,22 \mathrm{aA}$ & $56,48 \mathrm{bA}$ & $80,35 \mathrm{aB}$ & $66,19 \mathrm{bA}$ \\
\hline S5 & $49,77 \mathrm{aA}$ & $51,37 \mathrm{aA}$ & $65,63 \mathrm{aA}$ & $56,60 \mathrm{bA}$ & $91,60 \mathrm{aC}$ & $71,00 \mathrm{bB}$ \\
\hline \multicolumn{7}{|c|}{ Tempo de armazenamento (dias) } \\
\hline & \multicolumn{2}{|c|}{9} & \multicolumn{2}{|c|}{12} & \multicolumn{2}{|c|}{15} \\
\hline Sanificantes & $\mathrm{C} 1$ & $\mathrm{C} 2$ & $\mathrm{C} 1$ & $\mathrm{C} 2$ & $\mathrm{C} 1$ & $\mathrm{C} 2$ \\
\hline S1 & $80,13 \mathrm{aA}$ & $71,25 \mathrm{bA}$ & $86,00 \mathrm{aA}$ & $76,03 \mathrm{bA}$ & $95,83 \mathrm{aA}$ & $82,99 \mathrm{bA}$ \\
\hline $\mathrm{S} 2$ & $80,29 \mathrm{aA}$ & $71,06 \mathrm{bA}$ & $86,04 \mathrm{aA}$ & $76,00 \mathrm{bA}$ & $95,71 \mathrm{aA}$ & $83,89 \mathrm{bA}$ \\
\hline S3 & $80,34 \mathrm{aA}$ & $71,27 \mathrm{bA}$ & $86,09 \mathrm{aA}$ & $75,93 \mathrm{bA}$ & $96,20 \mathrm{aA}$ & $83,94 \mathrm{bA}$ \\
\hline S4 & $85,86 \mathrm{aB}$ & $74,80 \mathrm{bB}$ & $91,21 \mathrm{aB}$ & $78,88 \mathrm{bB}$ & $96,79 \mathrm{aA}$ & $90,26 \mathrm{bB}$ \\
\hline S5 & $98,38 \mathrm{aC}$ & $77,46 \mathrm{bC}$ & $95,08 \mathrm{aC}$ & $81,76 \mathrm{bC}$ & $96,71 \mathrm{aA}$ & $92,18 \mathrm{bC}$ \\
\hline
\end{tabular}

*Médias seguidas da mesma letra minúscula nas linhas e maiúscula nas colunas representam semelhanças estatísticas entre os cortes e os sanificantes, respectivamente, a 5\% de probabilidade, pelo teste de Scott-Knott.

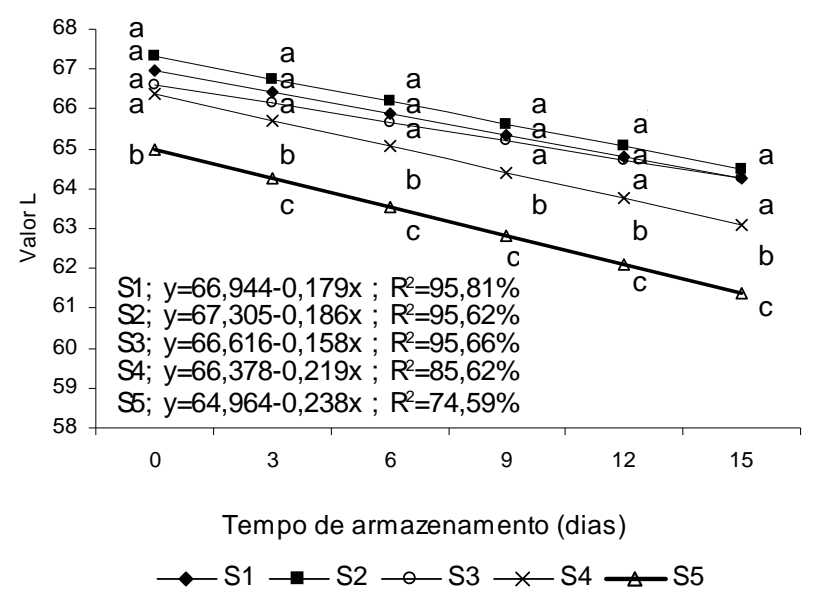

Figura 4 - Valores médios, equação de regressão e coeficiente de determinação do valor $\mathrm{L}^{*}$ em pequi minimamente processado submetido a tratamentos com $\mathrm{NaClO}$ e $\mathrm{H}_{2} \mathrm{O}_{2}$, em diferentes concentrações, armazenado a \pm $6^{\circ} \mathrm{C}$ por 15 dias.

*Médias seguidas da mesma letra entre as equações de regressão representam semelhanças estatísticas entre os sanificantes, a 5\% de probabilidade, pelo teste de ScottKnott.

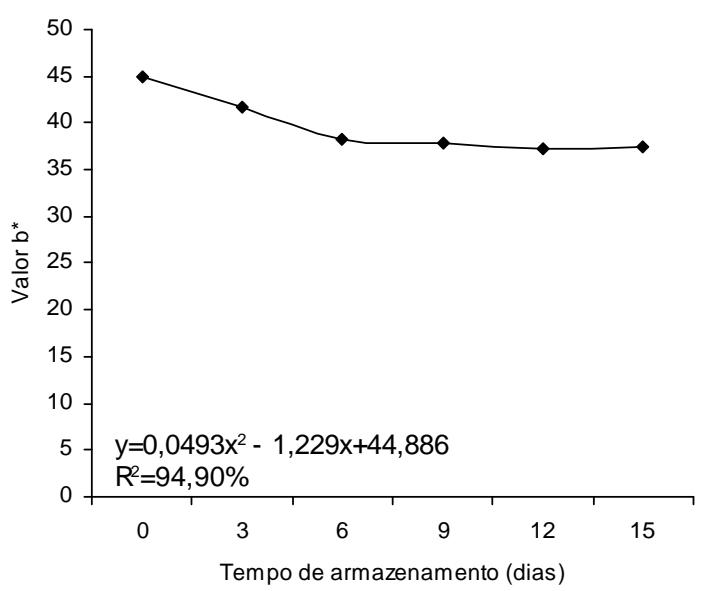

Figura 5 - Valores médios, equação de regressão e coeficiente de determinação da coordenada $b^{*}$ em pequi minimamente processado submetido a tratamentos com $\mathrm{NaClO}$ e $\mathrm{H}_{2} \mathrm{O}_{2}$, em diferentes concentrações, armazenado a $\pm 6^{\circ} \mathrm{C}$ por 15 dias.

\section{CONCLUSÕES}

$\mathrm{O}$ armazenamento de pequi minimamente processado a $6 \pm 1^{\circ} \mathrm{C}$ e $90-95 \%$ de UR é marcado pelo seu 
escurecimento, acompanhado pela ascensão da atividade das enzimas polifenoloxidase e peroxidase, notadamente por meio da coordenada $a^{*}$.

Os caroços fatiados apresentaram maior atividade das enzimas PFO e PER em relação aos caroços inteiros, e os caroços sanificados com $\mathrm{H}_{2} \mathrm{O}_{2}$ apresentaram maior atividade de PER que aqueles tratados com os demais sanificantes e o controle, resultando o escurecimento do produto com o armazenamento.

O fatiamento dos caroços de pequi promoveu uma redução na vida de prateleira quando comparado com os caroços inteiros, em razão, sobretudo do escurecimento do produto, resultando em 9 dias e 12 dias, respectivamente.

\section{AGRADECIMENTOS}

Os autores agradecem ao $\mathrm{CNPq}$, à CAPES e à FAPEMIG pelo suporte financeiro.

\section{REFERÊNCIAS BIBLIOGRÁFICAS}

ARRUDA, M.C.; JACOMINO, A.P.; PINHEIRO, A.L.; RIBEIRO, R.V.; LOCHOSKI, M.A.; MOREIRA, R.C. Hydrotermal treatment favors peeling of 'Pêra' sweet Orange fruit and does not alter quality. Scientia Agricola, Piracicaba, n.65, p.151-156, 2008.

BRAVERMAN, J.B.S. Vitaminas. In: Introduccion a la bioquímica de los alimentos. Barcelona: Omega, 1967. p.206-241.

BRECHT, J.K. Physiology of lightly processed fruits and vegetables. Hortscience, Alexandria, v.30, n.1, p.18-22, Feb. 1995.

BRITTON, G. Carotenoids. In: HENDRY, G.F. (Ed.). Natural foods colorants. New York: Blackie, 1992. p.141148.

CHITARRA, M.I.F. Processamento mínimo de frutas e hortaliças. Viçosa, MG: Centro de Produções Técnicas, 1998. 88p.

CHITARRA, M.I.F.; CHITARRA, A.B. Pós-colheita de frutos e hortaliças: fisiologia e manuseio. 2.ed. Lavras: FAEPE, 2005. 785p.

CROSS, J. Pigments in fruit. London: Academic, 1987. $303 p$.

DUNFORD, H.B.; STILLMAN, J.S. On the function and mechanism of action of peroxidases. Coordination

Chemistry Review, Lausanne, v.19, p.187-251, 1976.
FLURKEY, W.H.; JEN, J. Peroxidase and polyphenol oxidase activities in developing peaches. Journal of Food Science, Chicago, v.43, p.1826-1828, 1978.

\section{INTERNATIONAL FRESH-CUT PRODUCE}

ASSOCIATION. Fresh production. Disponível em: 4http://Www.fresh-cuts.orgs. Acesso em: 29 out. 2009.

KING JUNIOR, A.D.; BOLIN, H.R. Physiological ad microbiological storage stability of minimally processed fruits and vegetables. In: OVERVIEW OUTSTANDING SYMPOSIA IN FOOD SCIENCE \& TECHNOLOGY, 1 ., 1988, New Orleans. Proceedings... Chicago: Institute of Food Technologists, 1989. p.132-135.

LEE, S.K.; KADER, A.A. Preharvest and postharvest factors influencing vitamin $\mathrm{C}$ content of horticultural crops. Postharvest Biology and Technology, Amsterdam, v.20, n.3, p.207-220, Nov. 2000.

MARTINEZ, M.V.; WHITAKER, J.R. The biochemistry and control of enzymatic browing. Trends in Food Science \& Technology, Oxford, v.6, n.6, p.195-200, 1995.

MATSUMO, H.; URITANE, I. Physiological behavior of peroxidase enzymes in sweet potato root tissue injured by cutting or black root. Plant and Cell Physiology, Tokyo, v.13, n.6, p.1091-1101, 1972.

NUNES, E.E.; VILAS-BOAS, E.V.B.; XISTO, A.L.R.P.; LEME, S.C.; BOTELHO, M.C. Avaliação de diferentes sanificantes na qualidade microbiológica de mandioquinha-salsa minimamente processada. Ciência e Agrotecnologia, Lavras, v.34, p.900-994, 2010.

RODRIGUES, L.J.; VILAS-BOAS, E.V.B.; PAULA, N.R.F.; ALCÂNTARA, E.M. Caracterização do desenvolvimento de pequi (Caryocar brasiliense) temporão do Sul de Minas Gerais. Pesquisa Agropecuária Tropical, Goiânia, v.39, n.3, p.260-265, jul./set. 2009.

ROLLE, R.S.; CHISM, G.W. Physiological consequences of minimally processed fruits and vegetables. Journal of Food Science, Chicago, v.10, n.3, p.57-178, May/June 1987.

STROHECKER, R.; HENNING, H.M. Analisis de vitaminas: metodos comprobados. Madrid: Paz Montalvo, 1967. 428p. 
SUBRAMANIAN, N.; VENKATESH, P.; GANGULI, S.; SINKAR, V.P. Role of poliphenol oxidase and peroxidase in the generation of black tea theaflavins. Journal of Agriculture and Food Chemistry, Easton, v.47, n.7, p.2571-2578, July 1999.

TEISSON, C. Le brunissement interne de l'ananas: Ihistorique; II-materiel et methodes. Fruits, Paris, v.34, n.4, p.245-281, 1979.

VALDERRAMA, P.; MARANGONI, F.; CLEMENTE, E. Efeito do tratamento térmico sobre a atividade de peroxidase (POD) e polifenoloxidase (PPO) em maçã
(Mallus comunis). Ciência e Tecnologia de Alimentos, Campinas, v.21, n.3, p.321-325, set./dez. 2001.

VILAS-BOAS, B.M.; NUNES, E.E.; LIMA, L.C.O.; VILASBOAS, E.V.B.; PINHEIRO, J.R. Qualidade de mangas 'Tommy Atkins' minimamente processadas submetidas a diferentes tratamentos químicos. Revista Brasileira de Armazenamento, Viçosa, v.31, p.44-51, 2006.

VILAS-BOAS, E.V. de B. Frutas minimamente processadas: pequi. In: ENCONTRO NACIONAL SOBRE PROCESSAMENTO MINIMO DE FRUTAS E HORTALIÇAS, 3., 2004, Viçosa, MG. Anais... Viçosa, MG: UFV, 2004. p.122-127. 